\title{
Gender and Sector Related Differences in Emotional Social Intelligence of University
}

\author{
Teachers \\ * Dr. Fazli Khaliq, SST (Corresponding Author) \\ ** Dr. Said Saeed, Principal \\ *** Dr. Allah Nawaz
}

\begin{abstract}
The drive of the study was to investigate gender and sector-related differences of emotional-social intelligence of university teachers. The objectives of this research work were to; examine the emotional-social intelligence of university teachers, find gender-related differences in the emotionalsocial intelligence of teachers, and to assess sector-related differences in the emotional-social intelligence of university teachers. A mixed-method approach was followed to gain the objectives. Teaching faculty and learners of four universities of Khyber Pakhtunkhwa were the targeted population of this research work. 100 teachers and 350 students were taken through simple random and judgmental techniques. Data were collected from the respondents through Questionnaires and interviews, the collected data were then analyzed through descriptive and inferential statistics. Considerable differences in males and females were noticed between Emotional Social intelligence (ESI) of teachers, while very small differences were found in sector related. It is recommended that teachers may provide trainings, workshops, and awareness seminars on emotional-social intelligence to enhance the effectiveness of their instruction and to reduce the intentional and unintentional emotional abusing practices in the classroom.
\end{abstract}

Keywords: Intelligence, Emotional Intelligence (EI), Social Intelligence (SI), Teacher Introduction

The talent of the human being to act with purpose and spirit is the actual intelligence (Wechsler, 1958). Social intellect is the ability to diagnose and care about individuals, and expression concert judiciously in communal conditions (Gardner, 1983). As a bright aspect, EI is an arrangement of abilities, designs, and behaviors to know and normalize the feelings of self and others toward a fruitful environmentally friendly version (Seal \& Andrews-Brown, 2010).

Furthermore, Bar-On(2000) defines emotional-social intelligenceas a common construct of interconnected, emotive and societal abilities, talents, and enablers that govern how successfully we comprehend and direct ourselves, comprehend others and communicate with them, and deal with dayto-day stresses.

Likewise, the teacher has different tasks while handling the classroom environment. These tasks are classroom management, sound preparation through lesson plan, application of best teaching methodology, positive interactions with students, and pragmatic approach to the use of emotionalsocial intelligence during the teaching-learning process (Clotfelter, Ladd \& Vigdor, 2005).

The change of any educational system is closely related to the eminence of its teachers and that is why teaching is the most honorable among all professions and the teachers are called the nations' mind makers. However, he can perform his or her various responsibilities well if he or she were professionally and personally efficient (Kumar \& Ritzhaupt, 2015).

Emotionally and socially equipped teachers ensure that all students master basic skills and have strong backgrounds in other subject areas as well as enhance their own and students' social and emotional skills. Research indicates that social and emotional skills are associated with success in many areas of life, including effective teaching, student learning, quality relationships, and academic

* Elementary \& Secondary Education, Khyber Pakhtunkhwa Email: khaliq78@yahoo.com

** Elementary \& Secondary Education, Khyber Pakhtunkhwa Email: syedsaeed54@ gmail.com

*** Department of Public Administration, Gomal University, Dera Ismail Khan, Pakistan

Email: profallahnawaz@gu.edu.pk 
performance. Moreover, a recent meta-analysis of studies showed that programs designed to enhance social and emotional learning significantly improve students' social and emotional competencies as well as academic performance. For the overall improvement of students, teachers with intelligence, emotional and social intelligence are the need of the hour (Greenberg et al, 2003).

\section{Objectives}

Objectives of this research work were.

1. To examine emotional-social intelligence (ESI) of university teachers

2. To investigate gender-related differences in ESI of university teachers.

3. To recognize sector-related differences in ESI of teachers at the university level

\section{Research Questions}

1. What is the emotional-social intelligence of university teachers?

2. Is there any gender-wise differences in ESI of teachers at university teachers?

3. Are there any sector-wise differences in ESI of teachers at university teachers?

\section{Literature Review}

Emotional intelligence is emerging for an innovative aptitude construct. Salovey and Mayer (1990) introduced it. Later, it faced so many challenges and continuous hot debates, but its efficacy is still interrogated even these days (Landy, 2006). Someone called it SI, someone emotional intelligence and even Goleman (2006) described it as the new-fangled science of human interactions.

Dawda and Hart (2000) introduced psychometric intelligence which grounded on psychological and social paradigms. According to Weber and Westmeyer (2001), psychologists called it academic intelligence or psychological assessment. Later, this construct was called emotional (Salovey \& Mayer, 1990), practical (Wagner \& Sternberg, 1985), or successful intelligence (Sternberg, 1997) as new ability constructs.

The Emotional intelligence (EI) construct was first made known a hundred years before. It was also recognized that the intellectual endeavor done by Thorndike (1930) on social intelligence (SI) was the most basic effort on emotional intelligence (Bar-On, 2006; Gardner, 1983). Gardner anticipated the manifestation of dissimilar kinds of intelligence in person containing the conceptualizations of emotional intelligence (EI) and social intelligence (SI). SI is the capability of perceptive, appreciative, handling, and responding to feelings, sentiments, excitements, passions, and sensations, among others. Emotional intelligence is the skill of appreciation, consideration, management, and retorting to one's self feelings, sentiments, excitements, passions, and sensations. Gardner believed that these kinds of intelligence are as significant as the type of intelligence characteristically calculated by Intelligent Quotient- IQ (Petrides, 2011). These research works provide a base for the creation of Emotional intelligence that is a new terminology for the researchers.

Salovey and Mayer (1990) familiarized the construct of EI, which gained fame after the book of Goleman in which he said that emotional intelligence is more powerful than IQ. After this, the researchers introduced new notions, theories, and models about emotional intelligence. The most prominent models among these were ability models, trait models, and mixed models. The first one deal with mental abilities, the second one is related to a set of intellectual aptitudes to resolve those issues which are linked to sentimentalism and variegated representations- interest, hopefulness, and self-assurance, among others (Fernandez- Berrocal \& Ruiz, 2008).

Spoken skill, recollection, dispensation, and talent features of intelligence are respectively like the emotional intelligence to overcome emotional state and employing it to improve intelligence (Mayer, Salovey, \& Caruso, 2008). Emotional intelligence performs an essential role in the behavior of a person, presentation, enactment, and capability to deal with unforeseen events. Emotional intelligence also influences a person's aptitude to interconnect emotional state and frame of mind efficiently, successfully, and perfectly. Dearth of emotional intelligence frequently shows unwanted attitudinal and societal results (Mayer, Salovey, \& Caruso, 2008).

Emotional intelligence includes 'hot intelligences' also having a type of intelligence that covers 'communal, applied, and individual intelligences' (Mayer, Salovey, \& Caruso, 2004, p. 197). To make clear the dissimilarities between intelligence and its application, Fer (2004) clarified that Intelligent Quotient aid in logical and oral ability in a good manner but they do not measure creativity, pragmatic knowledge, and other propensities in resolving issues. Thus, just having intelligence, does not give assurance of achievement in the allocated responsibilities. Moreover, intelligence is the capability to make an impression on both psychological and somatic good fortune (Kotsou, Nelis, 
Grégoire, \& Mikolajczak, 2011). Emotional intelligence also changes social communications and influence work capability. Kotsou, Nelis, Grégoire, and Mikolajczak (2011) emphasized numerous profits of emotional intelligence for groups and individuals ranging from less important labor connected stresses, attitudinal glitches, behaviors, talent to show the way, joint enthusiasm, job satisfaction, and superior feelings of possession, dedication and faithfulness with the group. Identifying social and emotional intelligence is supportive in forecasting job performance (Cherniss, 2010).

Emotional state of mind has an emotional impact on instruction (Arghode, 2014). Thus, it is indispensable to understand teachers' sentiments for understanding instructors and instruction (Arghode, 2014). In reality, Deary, Strand, Smith, and Fernandes (2007) proposed sentiments are the means through which gaining knowledge can be realized. Feelings and sentiments improve gaining knowledge and make it real. When we connect to an idea, by making an emotive connection, the idea remains in our retention for a long period. In the same way, if someone is not self-assured that an idea is value discovering, no difficulty what we perform or how considerable someone is enforced in education the idea, our gaining knowledge will not be improved. Thus, there is a link between emotional intelligence and gaining knowledge.

Highly emotionally intelligent persons have the advantage because emotional intelligence specifies a competence to improve expertise in learning to retort passionately. However emotional competence is attained or experienced talent reliant on emotional intelligence which pays toward extraordinary job accomplishment (Zeidner, Matthews, \& Roberts, 2004). Accordingly, emotional competence is the use of emotional intelligence which also differentiates between persons who all possess intelligent quotient and emotional intelligence but some practice the proficiency superior to others. Mayer, Salovey, and Cruso (2008) point out, among inferior rank emotional competence comprise aptitude to identify sentiments whereas the superior rank abilities contain aptitude to overcome sentiments. Therefore, researchers agree to have emotional competence which is the skill to employ emotional intelligence. Emotional competence is vibrant in applying emotional intelligence for better task performance. Approximately paybacks contain improved talent to control sentiments, remain more communal and mental capability, minimize tension and problematic behaviors, and complete improvement in societal communications and association (Kotsou, Nelis, Grégoire, \& Mikolajczak. 2011). Research also confirmed an improved emotional intelligence among organizational learners and project administrators (Nicholas, Rowlands \& Jamali, 2010).

Emotional intelligence can be enhanced by the provision of a socially designed training program because social intelligence is quite dissimilar from emotional brainpower. Similarly, Weis and Arnesen (2007) have also backed the same outlook 'that speeches, interpretations, and out-dated exercise projects are never effective in enlightening emotional intelligence. Besides, refining emotional intelligence is thought-provoking and needs time and struggle for the reason it is about moulding attitude fashioned deeply through earlier revelations (Weis \& Arnesen, 2007). Therefore, methods that raise the spirits of learners to self-assess and judgmentally review their attitudes are more appropriate (Weis \& Arnesen, 2007). Sentiments can influence instruction in several ways containing the choice of objectives, agreed through instructor for the learners, struggling to accomplish constructive results in instruction, and elasticity to show modification in search of crucial aims (Sutton \& Wheatley, 2003). Furthermore, learners may read instructors' exhibition of adverse sentiments which influence learning of students (Sutton \& Wheatley, 2003). In the same position, teachers' connection with learners significantly affects students' education (Sutton \& Wheatley, 2003). The robust emotional skills, emotional competence, the knowledge, expertise, proper application of emotional intelligence, the capability of making a congenial classroom environment on the part of instructors, improves learning for instruction efficiently are significant. Fer (2004) emphasized that if instructors understand learners better and uphold a hale and hearty association with the learners, learners tend to show better performance.

Emotions and enthusiasm are a foundation dynamism and vitality. Constructive feelings and sentiments energize us positively whereas adverse feelings and sentiments weaken our vitality and liveliness. Therefore, the proper handling of sentimentalism is imperative in the life of each person (Kotsou, Nelis, Grégoire, \& Mikolajczak, 2011). Emotional intelligence works on understanding about sentiments and sensations. Mayer, Salovey, and Caruso (2004) emphasize that understanding and increasing emotional awareness is very important. Grounded on the above debate, feelings, 
sentiments, sensation, emotional and mental state of mind, and emotional intelligence's critical role in instruction and learning cannot be disregarded, particularly as passions put influence upon 'instructors' instruction, and learners' (Sutton \& Wheatley, 2003), Emotions and sentiments also influence the construction and arrangement of teaching on the part of teachers, classification of constructs, and logical thinking of the teachers (Sutton \& Wheatley, 2003). EI also influences students' aptitudes and talents to learn, be self-confident, be optimistic, be positive, exhibit the mind's eye, and solve difficulties, grip constant worry, display dignity, and get emotional stability (Monsen, Ewing, \& Kwoka, 2014).

ESI is the mixture of SI (Sternberg, 1985) and EI (Goleman, 1998). Intelligence is the ability of a person to respond quickly to the situation (Goleman, 1998). It is the combination of intrapersonal and interpersonal aspects. Intrapersonal intelligence is the other name of emotional while interpersonal intelligence is social intelligence. Gardner (1983) gives details that the notion of individual intellect is the combination of intrapersonal and interpersonal intelligence. Additionally, Saarni (1990) refers to emotional competence as the group of eight interns connected emotive and societal talents. Moreover, it is said that social-emotional intelligence includes intrapersonal and interpersonal capabilities, expertise, and operational social conduct. Therefore, it is called ESI rather than EI or SI (Dong, Koper \& Collaco, 2008).

ESI is a comparatively current construct that observed attitudinal experiences and their influence on the performing of learners. Emotional social intelligence has proved potential in influencing the efficiency of present-day officialdoms. According to Cherniss (2000), the majority of competencies are related to higher enactment and achievement in the organization is emotive or societal, especially to emotional-social intelligence, many groups identify emotional-social intelligence as a set of passionate skills that permit individuals to practice sentiments to expedite looked-for results. As contended by Fisher and the best rationale for the latent significance of emotional-social intelligence is the application of sentiments in the environment which helps know the attitude of personnel in institutions. The catalogue of attitudes possibly affected by emotionalsocial intelligence contains miscellaneous results- work gratification, constructive work assertiveness, leadership capability, and self-efficacy and transformation management Carmeli, 2003).

Sternberg (1985) stressed on analytical, creative, and practical aspects of intelligence. It is applied brainpower that is most appropriate to ESI, making the availability of hope to researchers and enables to differentiate both practically and theoretically in assistance for accomplishment.

The modern ESI construct was coined by Bar-On (1985). He employed the terminology of emotional quotient (EQ), frequently used closely with emotional intelligence. He made available the conceptual association between previous notions of social intelligence and later notions of emotional intelligence. Bar-On (1985) projected that there are 15 competencies to measure the overall emotional and social operationalization which can be clustered into five constituents- intrapersonal, relational, managing constant worry, adaptableness, and broad-spectrum temperament. Salovey and Mayer (1990) defined emotional intelligence as the study of SI which contains the capability of managing sentiments of self and others, bringing discrimination and guiding philosophy and activities. Salovey and Mayer (1990) contented that SI makes available by and large speculative rationalization for the contracted range of emotional intelligence, which connects to a person's aptitude to properly recognize feelings of self and others, to differentiate between several sentiments, and practice this information to properly retort to the situation.

Self-awareness means when you know yourself that what are you going to do. This cognizance of the self is called self-awareness it has been described by many intellectuals. Mayer and Salovey (1990) define that self-awareness is a skill to observe themselves and others' emotional and mental state, to distinguish among them, and to employ this knowledge to monitor one's thoughts and performance. Goleman (1995) gave the definition it how leaders monitor themselves and their associations.

The Emotional intelligence Model is made up of four constructs, which make available a framework for looking at how cognizant we are of feelings and how we cope with sentiments, in ourselves and others. Each of the four constructs is made up of numerous competencies. Competencies are a set of attitudinal actions that can be established to generate achievement in each situation (Goleman, 2011). 
Self-Awareness is the soul of the emotional intelligence model and has a great effect on our aptitudes and capabilities to advance competencies in the other areas. It empowers us to know our attitudes and to keep these over times despite hindrances and impediments (Goleman, 2011).

Self-Management is about how efficiently, successfully, and adroitly we handle our sentiments and feelings; and how finely we regulate our retorts to new-fangled and thought-provoking situations (Goleman, 2011).

Social Awareness is related to how we handle the emotional state of other people. It permits us to be conscious of other people's state of mind, requirements, and apprehensions. Agreeing with other people's sentiments is based on constructing relationships (Goleman, 2011).

There are five aspects of Marlowe's (1986) model of SI-societal presentation expertise, vicarious talent, emotive poignancy and self-assurance, and attitude emotive poignancy is the application of emotionalism and self-assurance in societal circumstances is stranded on one's comfort level in societal conditions (Dong, Koper \& Collaco, 2008).

Relationship Management is the skill to put on emotive consideration and appreciation in interactions with others. This is the perceptible side to emotional intelligence (EI) and is strengthened by the competencies of awareness and management of the self and awareness of the others. Emotionally and socially intelligent people must involve persons and institutes with suitable methods, authorizing them to survive a more prolific, fervent, and focused life. The skill to understand, see, construe, take to mean, and reply to excitements and feelings of others has a vital impression on the specialized and individual achievement of others. Attaining a huge appreciation and superior handling of own passions and feelings can significantly influence others, improve performance, build stronger and collaborative relationships, increase self-confidence, and achieve higher levels of achievement individually and collectively (Goleman, 2011).

\section{Methodology}

An explanatory sequential mixed method strategy was adapted. Teachers and learners of two public and two private sector universities of Khyber Pakhtunkhwa were the population of this research work. There are (672) teachers and (22540) students in two public and two private universities of KP, According to HEC and development statistic Khyber Pakhtunkhwa (KP) (2017). Simple random and convenient sampling techniques were followed for the selection of respondents. The sample of the study was 100 teachers and 350 students. Questionnaires and in-depth interviews were used as inquiry tools to gather facts from the selected informants.

\section{Validity and Reliability of Research tools}

The research tool was validated through eight experts. The tool was minimized. All grammatical corrections were made accordingly. The repetition of some items was removed from the tool.

The Cronbach Alpha was applied to identify the reliability of the tool after the pilot study. It was .78 which fulfils the standard criteria.

Data Analysis

R.Q.1: - $\quad$ What is the observed level of ESI of university teachers?

Table 4.1 Overall emotional-social intelligence of university teachers

\begin{tabular}{lccccc}
\hline \multicolumn{1}{c}{ Sub-Constructs of ESI } & $\mathrm{N}$ & Minimum & Maximum & Mean & Std. Deviation \\
\hline Self-awareness & 450 & 15 & 40 & 32.92 & 4.471 \\
self-management & 450 & 20 & 40 & 31.83 & 4.339 \\
social awareness & 450 & 17 & 40 & 32.24 & 4.307 \\
relational management & 450 & 18 & 40 & 32.00 & 4.339 \\
\hline
\end{tabular}

Table 4.1describes the means scores and standard deviations of the sub-constructs of emotional-social intelligence with range (31.83 to 32.92). The highest mean score was that of selfawareness (32.92) with a standard deviation of 4.471 and the lowest mean score was that of selfmanagement (31.83) with a standard deviation of 4.339. Keeping in view the minimum and maximum scores of the mean scores, university teachers have above average level emotional-social intelligence.

R Q. 2: - What is gender difference in emotional-social intelligence at the university level? Table 4.2 Overall gender-wise differences in emotional-social intelligence

\begin{tabular}{llllll}
\hline Gender & Mean & Std deviation & t-value & Sig. level & Eta $^{2}$ \\
\hline Male & 137.46 & 15.78 & & & \\
Female & 120.91 & 15.19 & 2.29 & .032 & 0.16 \\
\hline
\end{tabular}


The table above describes the overall mean score of male and female respondents from the sample group of the study. Male mean scores 137.46 with std deviation 15.78 while the female means score 120.91 with std deviation 15.19 were recorded. These results showed a high level of emotionalsocial intelligence of male respondents than female respondents.

Furthermore, the same results were verified by the $t$ value 2.29 which was significant at .032 which is less than .05 . Thus, according to the above-mentioned analysis obtained from an independent sample t-test, male respondents are more emotional socially intelligent than female respondents.

However, according to eta ${ }^{2}$ results, these differences are very small.

Table 4.3Component -wise Gender comparisons of emotional-social intelligence

\begin{tabular}{lllccll}
\hline & Gender & Mean & $\begin{array}{c}\text { Std. } \\
\text { Deviation }\end{array}$ & t value & Sig level & Eta $^{2}$ \\
\hline Self-awareness & Male & 33.09 & 4.48 & 1.36 & .17 & .009 \\
& Female & 32.66 & 4.51 & & & \\
Self-management & Male & 32.09 & 4.30 & & .02 & 0.15. \\
& Female & 30.44 & 4.36 & 2.21 & .02 & \\
Social awareness & Male & 32.51 & 4.26 & & & 0.10 \\
\multirow{2}{*}{ Relational management } & Female & 31.48 & 4.33 & 2.23 & .02 & \\
& Male & 32.19 & 4.48 & & & 0.14
\end{tabular}

Table 4.3 shows mean scores, $\mathrm{t}$ value, and eta ${ }^{2}$ of teachers' emotional-social intelligence from male and female points of view. The mean score of males (33.09) is better than female (32.66) on the self-awareness which show that male participants are more self-aware than female respondents. Whereas the $t$-value shows that this difference is insignificant, however, eta ${ }^{2}$ shows a small difference in their mean values.

Similarly, on self-management, the mean score of males (33.09) is better than females (30.44) show that males are more self-managed than females. The values are noteworthy at the significant level .02. Likewise, the mean score of social awareness with $t$ value 2.23 which is important as revealed by level of significance (.02). The values prove that males are socially strong than female participants.

On the other hand, the mean difference of relational management with t value 1.59 which is insignificant as demonstrated by level of significance (0.11). It is also illustrated that male participants are well managed in their relationships with others as compared to female respondents. However, Eta ${ }^{2}$ values show a small effect size in all components of emotional-social intelligence

Table 4.4 Overall sector-related differences of emotional-social intelligence

\begin{tabular}{llllll}
\hline Sector & Mean & Sd. deviation & $\mathrm{t}$ value & Sig, level & $\mathrm{Eta}^{2}$ \\
\hline Public & 125.60 & 19.79 & & & \\
Private & 127.36 & 19.43 & -1.19 & .231 & 0.08 \\
\hline
\end{tabular}

Table 4.4 shows that the overall mean score of private sector participants is better than public sector participants in Emotional Social Intelligence. Whereas T-test analysis shows that this difference is insignificant. The $\mathrm{Eta}^{2}$ value (0.08) shows a small effect size in sectors.

Table 4.5 Component-wise Sector related differences of ESI

\begin{tabular}{clccccc}
\hline Component & Sector & Mean & $\begin{array}{c}\text { Sd } \\
\text { Deviation }\end{array}$ & t value & Sig value & Eta $^{2}$ \\
\hline Self-awareness & Public & 32.91 & 4.22 & & \multirow{2}{*}{.16} & \\
& Private & 33.93 & 4.90 & -1.23 & & 0.002 \\
Self-management & Public & 31.81 & 4.33 & & .87 & 0.009 \\
& Private & 31.82 & 4.38 & -0.15 & & \\
Social awareness & Public & 32.35 & 4.67 & & 0.23 & 0.07 \\
& Private & 31.20 & 4.35 & 1.15 & & \\
Relational & Public & 31.97 & 4.25 & & & \\
management & Private & 32.07 & 4.46 & -0.28 & 0.77 & 0.02 \\
\hline
\end{tabular}


Table 4.5 describes mean scores and t value of emotional-social intelligence from dimensions of the sector. The mean score of the private sector (33.93) is better than the public sector (32.91) on Self-awareness which shows that private sector participants are more self-aware than public sector respondents. However, the t-value shows that this difference is insignificant.

On self-management, the mean score of public sector teachers (31.81) and private sector teachers (31.84) show that there are no differences. These values are insignificant as the level of significance 0.87 which higher than .05 . The mean score difference of social awareness is insignificant as shown by the level of significance (.23). It is revealed by the values that public sector participants are socially better than public sector respondents.

Similarly, the mean difference of relational management, the mean score with $t$ value 0.28 which is insignificant as shown by the significant value $(0.73)$. The Eta ${ }^{2}$ values $(0.002,0.009,0.07$, and 0.02) show trivial effect size in components of emotional-social intelligence in public and private sectors.

\subsection{Interaction Effect in gender-wise self-awareness in sector and discipline}
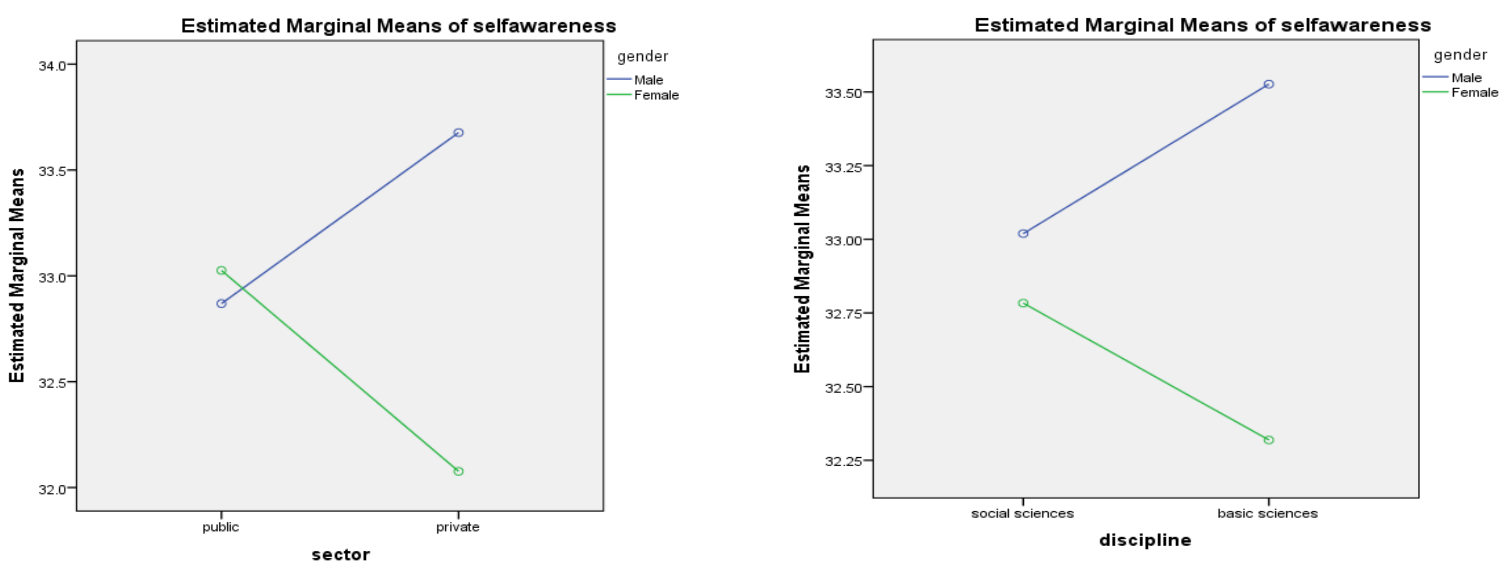

Figure 4.6 Interaction Graphs of Gender, sector, and discipline regarding self-awareness

The interactional effects in self-awareness of emotional-social intelligence among gender, sector, and discipline were calculated through two-way ANOVA which reflected that there is significant interaction effect among the groups.

Furthermore, the graphs also show that males and females have significant differences in the public sector while this difference is not significant in the private sector.

On the contrary, these differences in basic sciences are significant as compared to social sciences teachers in public and private sectors from the perspectives of self-awareness.

\subsection{Interaction Effect in gender-wise self-management in sector and discipline}
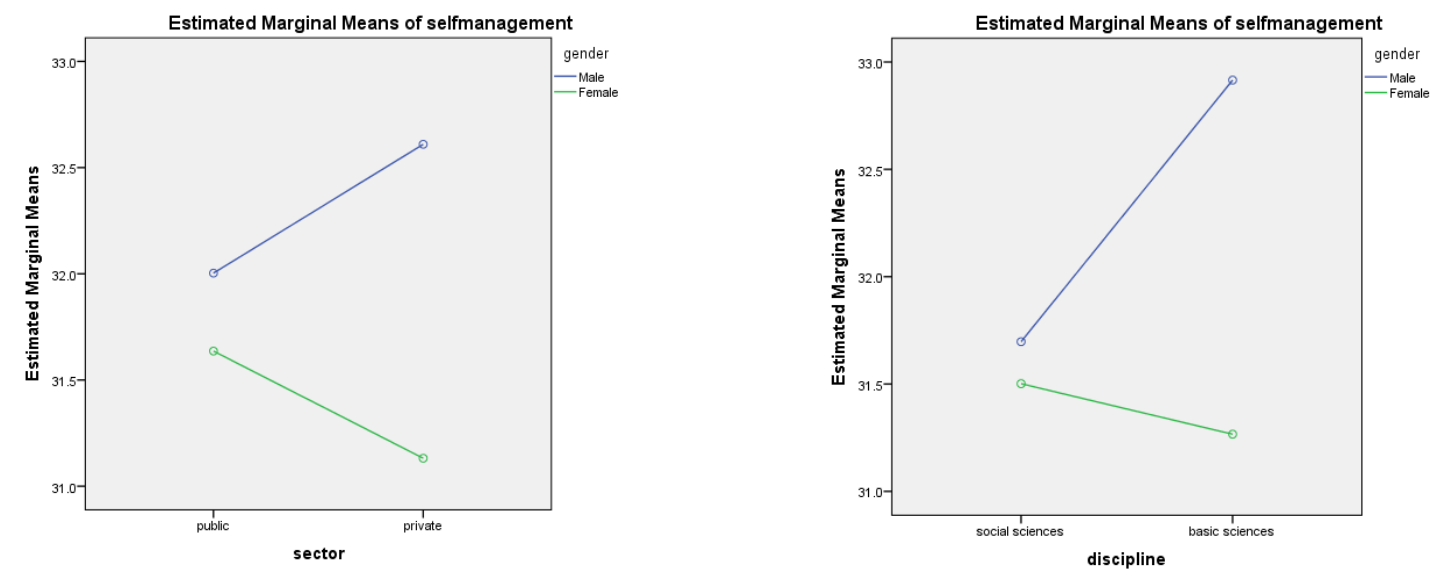

Figure 4.7 Interaction Graphs of Gender, sector, and discipline regarding self-management Interaction effect in emotional self-management among gender, sector, and discipline was entered in the two-way ANOVAs as gender, sector, and discipline.

There was a significant interaction effect in self-management of emotional-social intelligence 
among gender, sector, and discipline. It was found that there is no significant interaction between males and females in the public and private sectors. It was found that there is a significant interaction effect in basic sciences and social sciences regarding self-management in the public and private sectors. It was also that there is no significant interaction between males and females in basic sciences and social sciences. However, in social sciences male and female are close as compared to basic science

\subsection{Interaction Effect in gender-wise social-awareness in sector and discipline}
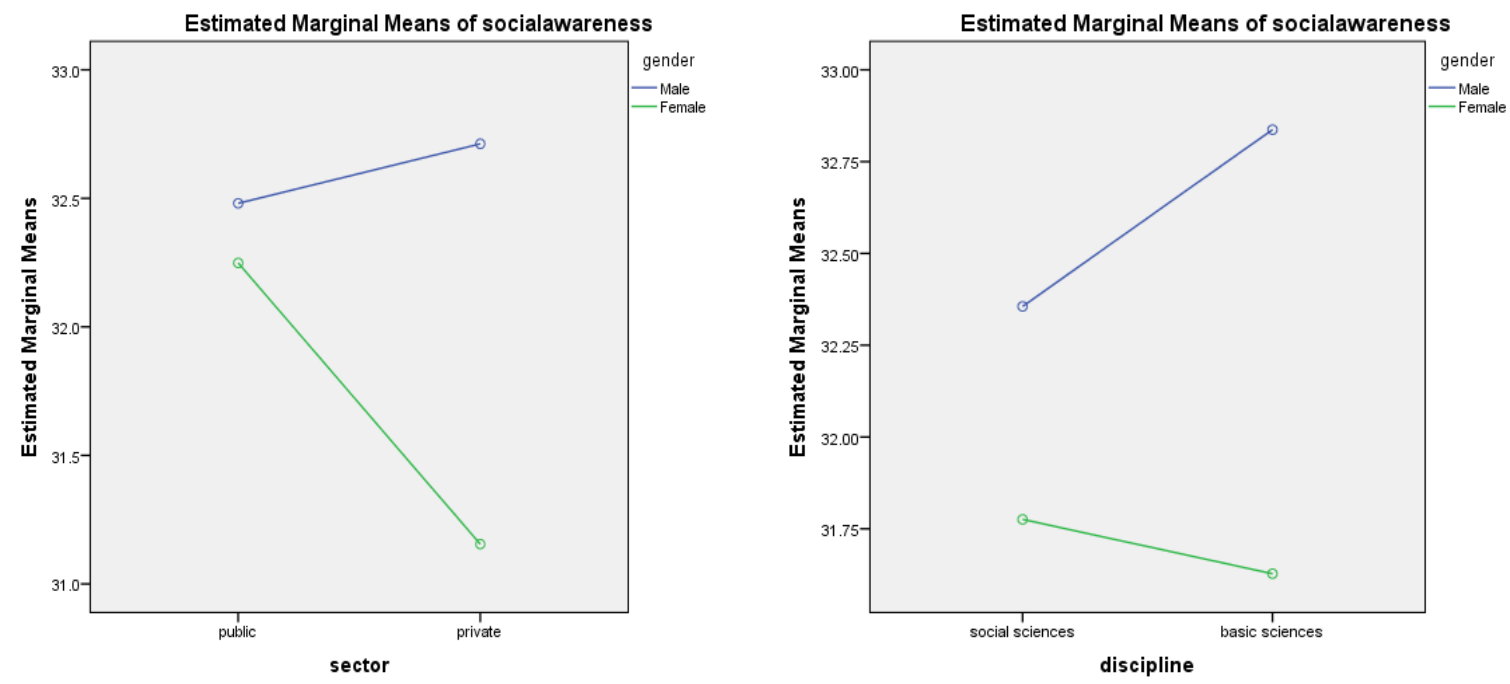

Figure 4.8 Interaction Graphs of Gender, sector, and discipline regarding social awareness

To find the interaction effect in emotional social awareness among gender, sector, and discipline was entered in the two-way ANOVAs as gender, sector, and discipline.

There was no significant interaction effect in social-awareness of emotional-social intelligence among gender, sector, and discipline. It was found that males and females have close interaction in the public sector as compared to the private sector. It was also found that there is no interaction effect in males and females regarding social awareness in basic sciences and social sciences. It was also that there is no significant interaction between males and females in basic sciences and social sciences. No interaction effect was found in basic and social sciences teachers in public and private sectors.

\subsection{Interaction Effect in gender-wise relational management in sector and discipline}
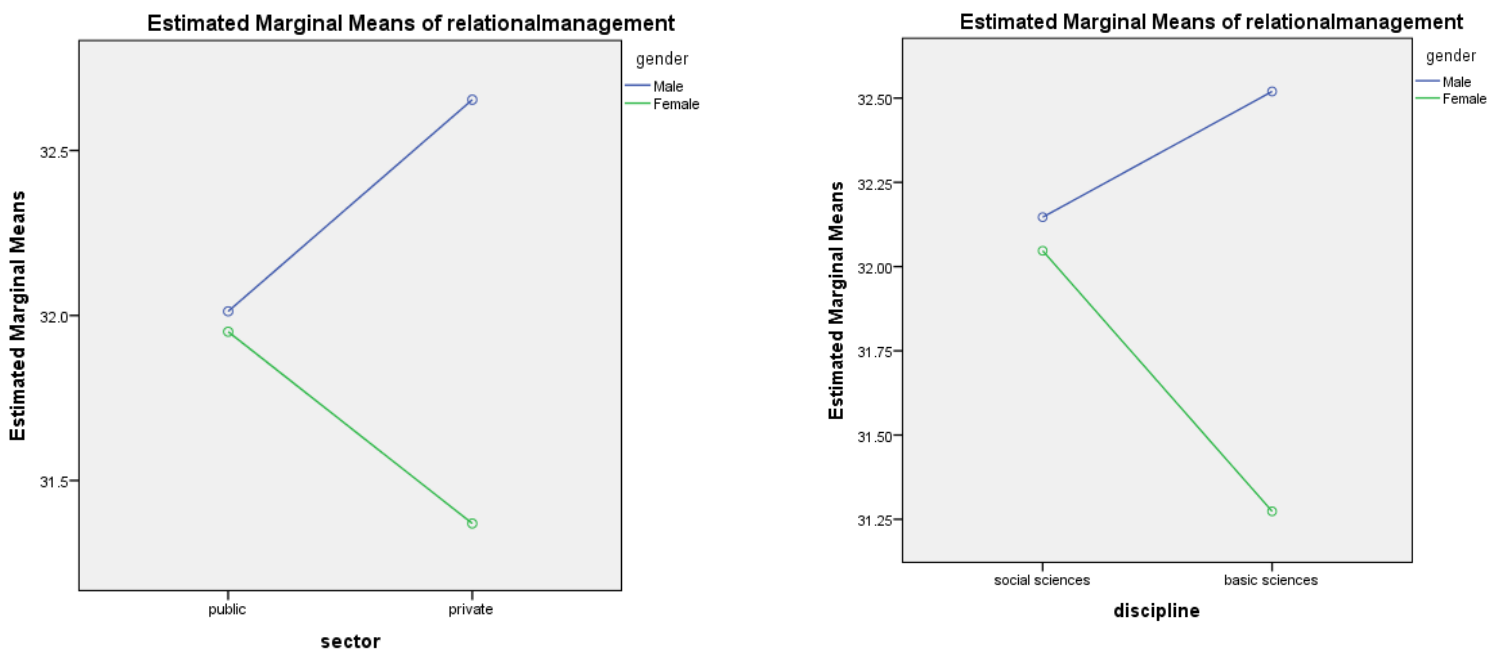

Figure 4.9 Interaction Graphs of Gender, sector, and discipline regarding relational management

To find the interaction effect in emotional relational management among gender, sector, and discipline was entered in the two-way ANOVAs as gender, sector, and discipline.

There was a significant interaction effect in relational management of emotional-social intelligence among gender, sector, and discipline. It was found that males and females have no 
interaction in the public and private sectors. However, interaction in males/females is comparatively better in the public sector than in the private sector. It was found that the interaction effect of relational management in basic sciences teachers is significantly better than social sciences in the public and private sectors. It was also found that there is no significant interaction between males and females in basic sciences and social sciences. However, females and females in the social sciences are close as compared to basic sciences.

\section{Findings}

Findings of the research work were.

1. The overall mean scores of university teacher's self-awareness, self-management, social awareness, and relational management is $32.92,31.83$, and 32.24. and 32.00 respectively (table 4.1)

2. The overall $\mathrm{t}$ value of gender-wise teachers emotional-social intelligence is 2.29 which was significant at .024 and eta ${ }^{2}$ was 0.16 (table 4.10 )

3. The overall $\mathrm{t}$ values of component-wise emotional-social intelligence were 2.21 (selfmanagement) and 2.23 (social awareness) which were significant at .02 while 1.36 (selfawareness) and 1.59 (relational management) which were not significant at significant level .17 and .11 respectively. The eta ${ }^{2}$ were $.009,0.15,0.10$ and 0.14 (table 4.11 )

4. The overall $t$ value of sector-wise teacher's emotional-social intelligence is -1.19 which was insignificant at .231 and eta square was 0.08 (table 4.12)

5. The t values of sector-wise emotional self-awareness, self-management, social awareness, and social management were $-1.23,-0.15,1.15$, and -0.28 noteworthy at significant level $.16, .87$, .23 , and .77 (Table 4.13)

6. The overall $t$ value of discipline-wise teacher's emotional-social intelligence was 2.09 which was significant at .035 significant level (table 4.14)

7. The $t$ values of discipline-wise emotional self-awareness, self-management, social awareness, and social management are $1.359,1.474,1.491$, and 1.213) which were significant at significant level .021, .023, .000 and .037 (table 4.15)

8. The ANOVA results indicate interaction for self-awareness between male and female in sector and discipline (figure 4.1)

9. The ANOVA results indicate interaction for self-management between male and female in sector and discipline (figure 4.2)

10. The ANOVA results indicate interaction for social awareness between male and female in sector and discipline (figure 4.3)

11. The ANOVA results indicate interaction for relational management between male and female in sector and discipline (figure 4.4)

The information gained from the interviews of the students regarding the ESI of teachers, Students partially favor the quantitative data of emotional-social intelligence and components. From qualitative data, the major themes of emotional-social intelligence and classroom learning environment were those which favor quantitative components i.e., self-awareness, relational management, social awareness, cohesion, support, involvement, equity, motivation, and others.

\section{Conclusion}

The major conclusions of the study were.

1. Keeping in view the minimum and maximum scores of the mean scores, it is concluded that most university teachers have above-average levels of emotional-social intelligence.

2. It was concluded that overall male university teacher's emotional-social intelligence was better than female teachers, but the eta square value shows that the difference between male and female is small.

3. It was concluded that male teachers have more emotional self-awareness, self-management, social awareness, and social management in comparison to female teachers. The eta squares results show a small interaction effect.

4. It was concluded that on the whole private sector participants are better than public sector participants in Emotional Social Intelligence. The eta square value shows a small interaction effect.

5. It was concluded that teachers from private sector universities are more self-aware, selfmanaged, and more relationally managed than public sector university teachers while public 
sector university teachers were more socially aware as compared to private sector university teachers. The eta square values show a trivial interaction effect.

6. It was concluded that in general basic sciences university teachers' emotional-social intelligence were better than social sciences teachers.

7. In conclusion, the results of the study reveal that basic sciences teachers were more selfaware, self-managed while social sciences teachers were socially aware and relationally managed than basic sciences teachers.

8. It was concluded that major themes of emotional-social intelligence are emotional selfawareness, self-management, social awareness, and relational management, and was found from the views of the informants that emotional-social intelligence of teachers significantly affects the classroom learning environment.

\section{Discussion}

It is shown by the literature that highly socially intelligent persons are especially sociable, caring, kind, considerate, more adjustable, and well-organized in coping with several societal matters and prosperous in society (Birknerová, Frankovský, \& Zbihlejová, 2013). These two studies favor finding no. 1, 2, 3, and 4 of the study. Social intelligence has been also connected to constructive results (Birknerová et al., 2013) supports the findings of the study. The studies of Nagra, (2014); Saxena and Jain (2013) favor these findings by finding professed reputation significantly linked with social intelligence, and disfavouring by positing no link between educational performance and emotionalsocial intelligence. Emotional state of mind has an emotional impact on instruction (Palomera, Fernandez- Berrocal, \& Brackett, 2008) supports the findings. Goleman, Boyatzis\&Rey (1999) study favor the qualitative emerged themes of the study i.e. self-regulation, social skills, empathy, etc. Labbaf, Ansari \&Masoudi (2010) have shown a direct and positive association between emotional intelligence and learning organization dimensions, as well as shown the influence of emotional intelligence on the learning organization dimensions supports the findings. The results of research applied by (2006) showed a direct and large relationship between emotional intelligence and learning environment; Josmann (2006) suggested the positive and noteworthy correlation between emotional intelligence and working values of workers fully favor the results of this study. Mayer and Salovey (1997) think that there exists a positive relationship among the branches of emotional intelligence support the findings. The results of the study of Igbinovia (2016) and Okpara and Edwin, (2015) favor the findings of this study.

\section{Recommendations}

On the bases of results and assumptions of the study subsequent recommendations were made;

1. Based on the conclusion No 1, as the teachers at universities have above average level Emotional intelligence which was confirmed by the interview data too. Therefore, it was recommended that they may utilize their EI for enhancing students' Emotional intelligence as the interview data revealed that most students were unaware of EI, through direct counselling sessions and awareness seminars.

2. Further, it was recommended that teachers may also work on the confidence-building of students where close academic relationships and mutual trust between teachers and students are indispensable.

3. Based on the study results it was also recommended that at the university level there must be a counselling Center for teachers and students aimed at the solution of psychological problems and behavioral disorders.

4. For future researchers, it was recommended to design a study to investigate those factors that directly contribute and affect the development of Emotional intelligence of teachers and students.

\section{Practical Implication}

The practical implications of this paper are very impressive and expressive for both male and female teachers and students. The findings of the study are very significant for the public and private sector universities in connection with emotional and social intelligence.

\section{References}

Arghode, V. (2014). Emotional and Social Intelligence competence: Implication for Instruction. International Journal of Pedagogies and Learning, 8(2), 66-77. DOI:10.5172/ijpl.2013.8.2.66 
Bar-On, R. E., \& Parker, J. D. (2000). The handbook of emotional intelligence: Theory, development, assessment, and application at home, school, and in the workplace. Jossey-Bass.

Bar-On, R. (1988). The development of a concept of psychological well-being. Unpublished doctoral dissertation, Rhodes University, South Africa.

Carmeli, A. (2003). The relationship between emotional intelligence and work attitudes, behavior, and outcomes. Journal of managerial psychology.

Cherniss, C. (2010). Emotional intelligence: Toward clarification of a concept. Industrial and Organizational Psychology, 3(2), 110-126.

Clotfelter, C. T., Ladd, H. F., \&Vigdor, J. (2005). Who teaches whom? Race and the distribution of novice teachers. Economics of Education Review, 24(4), 377-392.

Dawda, D., \& Hart, S. D. (2000). Assessing emotional intelligence: Reliability and validity of the Bar-On Emotional Quotient Inventory (EQ-i) in university students. Personality and individual differences, 28(4), 797-812.

Dong, Q., Koper, R. J., \& Collaço, C. M. (2008). Social intelligence. Self-esteem, and İtercultural Communication Sensitivity. Intercultural.

Ewing, D. L., Monsen, J. J., \& Kwoka, M. (2014). Behavioral and emotional well-being of children following non-directive play with school staff. Educational Psychology in Practice, 30(2), 192203.

Fernández-Berrocal, P., \& Ruiz, D. (2008). Emotional intelligence in education.

Gardner, H. (1983). Frames of mind. New York: Basic Books.

Goleman, D. (2011). Leadership: The power of emotional intelligence.

Goleman, D. (1995). Emotional intelligence. New York: Bantam Books.

Greenberg, L. S., \&Paivio, S. C. (2003). Working with emotions in psychotherapy (Vol. 13). Guilford, J. P. (1968). Intelligence, creativity, and their educational implications. Edits Pub. Press.

Kotsou, I., Nelis, D., Grégoire, J., \& Mikolajczak, M. (2011). Emotional plasticity: conditions and effects of improving emotional competence in adulthood. Journal of applied psychology, 96(4), 827.

Mayer, J. D., Salovey, P., \& Caruso, D. R. (2008). Emotional intelligence: New ability or eclectic traits? American psychologist, 63(6), 503.

Mayer, J. D., \& Salovey, P. (1997). What is emotional intelligence: In P. Salovey, \& D. Sluyter (Eds.)? Emotional development and emotional intelligence: Implications for educators (pp. 3-31). New York: Basic Books.

Mayer, J. D., Salovey, P., \& Caruso, D. R. (2004). Mayer-Salovey-Caruso Emotional Intelligence Test (MSCEIT). Toronto, Canada: Multi-Health Systems, Inc.

Moss, F. A., \& Hunt, T. (1927). Are you socially intelligent? Scientific American, 137, 108-110.

Petrides, K. V. (2011). Emotional intelligence.

Ritzhaupt, A. R., \& Kumar, S. (2015). Knowledge and skills needed by instructional dEIgners in higher education. Performance Improvement Quarterly, 28(3), 51-69.

Salovey, P., \& Mayer, J. D. (1990). Emotional intelligence. Imagination, Cognition, and Personality 9, $185-211$.

Sternberg, R. J. (1985). Beyond IQ: A triarchic theory of human intelligence.

Seal, C. R., \& Andrews-Brown, A. (2010). An integrative model of emotional intelligence: emotional ability as a moderator of the mediated relationship of emotional quotient and emotional competence. Organization Management Journal, 7(2), 143-152.

Sutton, R. E., \& Wheatley, K. F. (2003). Teachers' emotions and teaching: A review of the literature and directions for future research. Educational psychology review, 15(4), 327-358.

Thorndike, E. L. (1930). Intelligence and its uses. Harper's Magazine 140, $227-235$.

Weber, H., \& Westmeyer, H. (2001). Die Inflation der Intelligenzen [The inflation of intelligences]. Perspektiven der Intelligenzforschung [Perspectives of Intelligence Research], 251266.

Wechsler, D. (1958). The measurement and appraisal of adult intelligence (4th Ed.). Baltimore, MD: The Williams \& Wilkins Company.

Weis, W. L., \& Arnesen, D. W. (2007). "Because EQ Can't Be Told": Doing Something about Emotional Intelligence. Journal of Organizational Culture, Communications and Conflict, 11(2), 113.

Zeidner, M., Matthews, G., \& Roberts, R. D. (2004). Emotional intelligence in the workplace: A critical review. Applied Psychology, 53(3), 371-399. 